\title{
Risk Decision Analysis of Logistics Purchasing Based on Mathematical Expectation
}

\author{
Fengying Wang, Zhixin Liang \\ School of Information, Beijing Wuzi University, Beijing, China \\ Email: wangfengying73@163.com
}

Received 16 March 2016; accepted 23 April 2016; published 26 April 2016

Copyright (C) 2016 by authors and Scientific Research Publishing Inc.

This work is licensed under the Creative Commons Attribution International License (CC BY). http://creativecommons.org/licenses/by/4.0/

cC) (7) Open Access

\begin{abstract}
The mathematical expectation value method is a commonly used method in risk decision-making. This paper studies the problem of how to arrange the purchase plan in order to get the maximum expected profit; considering the applicable principles of mathematical expectation, the decision method for getting the optimal decision scheme is given. Finally, we do simulation and stability analysis on an example and obtain the reasonable result. This result shows that mathematical expectation value method is effective in solving the problem of risk decision.
\end{abstract}

\section{Keywords}

\section{Mathematical Expectation, Logistics Purchasing, Risk Decision, Stability}

\section{Introduction}

Purchasing, as the very beginning of logistic activities, covers every steps from suppliers to demanders regarding products, technique, information and service. The logistical purchasing of modern companies is no longer the simple supply of production material. Instead of the most reasonable price, the least consumption and risk as well as the largest insurance are the main parts of supplying. Through the effective planning, organization and control of purchasing management activity, companies will choose the suitable purchasing method, style, quantity, frequency and location to ensure the normal process of business activity with limited source. Therefore, it is necessary to build the scientific, systematic, effective optimized logistics purchasing model to reduce costs for enterprises, accelerate capital turnover and improve enterprise management quality so as to gain power for sustainable development [1]. Wang [2] discussed the inventory cost control of enterprises with respect to supplier and inventory information management. 
In the process of logistics purchasing, purchasing risk cannot be avoided absolutely. For example, the supplier risk, order quantity risk, quality risk, delivery risk and transportation risk can all be regarded as the potential risks in the logistics purchasing. Therefore, people in charge need to make all kinds of risk decisions to reduce and control the potential risks and optimize logistics purchasing.

Risk decision is the one with incomplete information. It is based on the scientific analysis of risk and lost to choose the proper and satisfying techniques and methods from the many alternative solutions [3]. The main characters of the risk decision are: 1) there is a clear goal, such as profit or loss, that the decision maker is expected to achieve; 2) there are more than two natural states (such as the market), and the possibilities of a variety of natural states can be estimated or calculated; 3) there are more than two action options for decision making, and only one is selected; 4) the profit or loss values of various action plans in different natural states can be calculated.

Mathematical expectation is one of the important characters in probability theory. It plays a very important role in the economic management [4] [5]. Deng [6] and Wen et al. [7] resolved the economical decision questions by using the mathematical expectation, including investment decision and profit on sales. Zhang [8] studied the quantitative analysis of the risk system by the use of probability and statistics. Xu [9] introduced the application of mathematical expectation in logistics management such as making decisions, choosing the optimal purchase batch size and the optimal stock quantity. Peng [10] established principles of risk decision-making by the state probability and program expectations and obtained the stability analysis for risk decision-making program by the character of transfer probability.

In this paper, we will study the applicable principles of mathematical expectation value method in risk decision-making. We will do simulation and stability analysis on an example. The remainder of this paper is organized as follows. Section 2 describes the applicable principles of expectation value method. The simulation and stability analysis on an example are given in Section 3. Section 4 contains the conclusions of this work.

\section{Applicable Principle of Mathematical Expectation Value Method}

Taking into account that the ultimate goal of risk decision-making is to protect the economic benefits of enterprises, people can use the expectation value method, combined with the probabilities of the natural states in the logistical purchasing to analyze risks and choose solution.

Generally, in the problem of risk decision-making, a decision maker often faced a number of possible states, recorded as $\theta_{1}, \theta_{2}, \cdots, \theta_{n}$. They also have many choices, recorded as $a_{1}, a_{2}, \cdots, a_{m}$. For each solution program $a_{i}$ and each state $\theta_{j}$, there is the profit $v_{i j}$, so as to form the $m$ row $n$ column matrix $V=\left(v_{i j}\right)$, which is called payoff matrix. Due to the random occurrence of various states, before deciding the decision makers need to make reasonable estimates of the probability of the various state $\theta_{j}$, recorded as $P\left(\theta_{j}\right)=p_{j}$. Therefore, the expected revenue of the corresponding decision $a_{i}$ is $\sum_{j} p_{j} v_{i j}$. In this way, the risk decision problem can be concluded as: confirm the $a_{k}$, which makes

$$
\sum_{j} p_{j} v_{k j}=\max _{i}\left(\sum_{j} p_{j} v_{i j}\right) .
$$

This is the maximum expected profit criterion in risk decision problems.

Similarly, if it is easy to get cost $w_{i j}$ from solution program $a_{i}$ under $\theta_{j}$ condition, the commonly used decision criterion is the minimum expected cost criterion: confirm the solution program $a_{k}$, which makes

$$
\sum_{j} p_{j} w_{k j}=\min _{i}\left(\sum_{j} p_{j} w_{i j}\right) .
$$

The method of decision making is generally applicable to the following situations: 1) the probability of emergence is obvious objective and stable; 2) the decision doesn't solve the problem once but to solve the problem of repeated repetition; 3) the results of the decision will not have serious consequences for the decision makers. 


\section{Simulation on an Example}

In this section we do simulation on an example.

\subsection{Example Description}

One company produces and sells a health product. The storage cost is high and the producing material has a short quality guarantee period. In order to satisfy the producing need, ensure the material quality and save cost, this company decides to arrange the purchasing plan properly and enforce the management of raw material management. It makes an assumption according to the sales from last year (see Table 1).

It is assumed that the purchase price of raw materials is: 2200 Yuan per ton if purchased 5 ton once; 2000 Yuan per ton if purchased 8 ton once; 1900 Yuan per ton if purchased 10 ton once. The selling price of the product is 5000 Yuan/ton. If the product is not sold out the same day, 1000 Yuan per ton must be paid pay for the inventory costs.

For the raw material purchasing problems, the purchasers face 3 states, recorded as $\theta_{1}, \theta_{2}, \theta_{3}$, corresponding to the demands of $5,8,10$ (ton) respectively. There are also three decisions for the purchasers, recorded as $a_{1}, a_{2}, a_{3}$, corresponding to the purchase quantity of $5,8,10$ (ton) respectively. After calculation, it is easy to get the payoff matrix

$$
V=\left(v_{i j}\right)=\left(\begin{array}{ccc}
14000 & 14000 & 14000 \\
6000 & 24000 & 24000 \\
1000 & 19000 & 31000
\end{array}\right)
$$

Since $p_{1}=P\left(\theta_{1}\right)=0.5, p_{2}=P\left(\theta_{2}\right)=0.3, p_{3}=P\left(\theta_{3}\right)=0.2$, then the expected profit of $a_{1}, a_{2}, a_{3}$ are $E\left(a_{1}\right)=\sum_{j=1}^{3} p_{j} v_{1 j}=14000, E\left(a_{2}\right)=\sum_{j=1}^{3} p_{j} v_{2 j}=15000, E\left(a_{3}\right)=\sum_{j=1}^{3} p_{j} v_{3 j}=12400$.

Since $E\left(a_{2}\right)>E\left(a_{1}\right)>E\left(a_{3}\right)$, the revenue expectation of the program $a_{2}$ is the largest. So for this company, 8 ton raw material purchase is the best.

\subsection{Other Decision-Making Principle}

There is also a kind of decision-making principle, that is, to reduce the opportunity loss as much as possible. The so-called opportunity loss refers to: when the state $\theta_{j}$ occurs, we choose solution $a_{i}$, but we may not get the maxim profit. The difference between the benefit obtained by the decision $a_{i}$ and the maximum benefit that may be obtained is the opportunity loss, recorded as

$$
l_{i j}=\max _{k} v_{k j}-v_{i j} \text {. }
$$

In this way, we can also use the minimum expected loss to make a loss principle, which is $a_{k}$, making

$$
\sum_{j} p_{j} l_{k j}=\min _{i}\left(\sum_{j} p_{j} l_{i j}\right)
$$

For the above logistical purchasing problem, it can be calculated that

$$
L=\left(l_{i j}\right)=\left(\begin{array}{ccc}
0 & 10000 & 17000 \\
8000 & 0 & 7000 \\
13000 & 5000 & 0
\end{array}\right)
$$

Table 1. Estimates of demand for a food company.

\begin{tabular}{cc}
\hline Daily demand (ton) & Probability \\
\hline 5 & 0.5 \\
8 & 0.3 \\
10 & 0.2 \\
\hline
\end{tabular}


The expected losses of $a_{1}, a_{2}$ and $a_{3}$ are $\sum_{j=1}^{3} p_{j} l_{1 j}=6400, \sum_{j=1}^{3} p_{j} l_{2 j}=5400, \sum_{j=1}^{3} p_{j} l_{3 j}=8000$, respectively. So we should choose $a_{2}$ by the principle of minimum expected loss.

Generally, the principle of minimum expected loss is equivalent to the principle of maximum expected benefit.

\subsection{Stability Analysis}

For the risk decision problem, the expected return value of each program is obtained based on the probability estimation of various natural states. This estimate is based on past experience estimates (or projections). Because the estimation of the probability of the state is affected by many factors, the expected return value based on the probability of the state is not the same as the actual. Once the probability value has changed, whether the decision has been determined is still valid, has become a problem worthy of attention. Therefore, it is necessary to understand how the probability value changes in the decision making process, so as to test the applicable scope of the selection program and the ability to resist risks. This is stability analysis or sensitivity analysis of the decision making problem.

For the above raw material purchasing problems, once the probability changes, the program $a_{2}$ may fail. Therefore, there must be a stability analysis. On the precondition of the stability of the optimal program $a_{2}$, the allowable range of the probability of natural state must be calculated.

Suppose $P\left(\theta_{1}\right)=x_{1}, P\left(\theta_{2}\right)=x_{2}=1-x_{1}-x_{3}, P\left(\theta_{3}\right)=x_{3}$, then

$$
\begin{gathered}
E\left(a_{1}\right)=14000 x_{1}+14000\left(1-x_{1}-x_{3}\right)+14000 x_{3}=14000 \\
E\left(a_{2}\right)=6000 x_{1}+24000\left(1-x_{1}-x_{3}\right)+24000 x_{3}=24000-18000 x_{1} \\
E\left(a_{3}\right)=1000 x_{1}+19000\left(1-x_{1}-x_{3}\right)+31000 x_{3}=19000-18000 x_{1}+12000 x_{3} .
\end{gathered}
$$

If program $a_{2}$ is still the best solution, then

$$
\left\{\begin{array}{l}
E\left(a_{2}\right) \geq E\left(a_{1}\right) \\
E\left(a_{2}\right) \geq E\left(a_{3}\right)
\end{array}\right.
$$

Namely, $x_{1} \leq \frac{5}{9}, x_{3} \leq \frac{5}{12}$, since $x_{2}=1-x_{1}-x_{3}$, so $x_{2} \geq \frac{1}{36}$.

The results are as follows:

1) When $P\left(\theta_{2}\right)>\frac{1}{36}, E\left(a_{2}\right)>E\left(a_{i}\right)(i=1,3), a_{2}$ is the best solution;

2) When $P\left(\theta_{2}\right)<\frac{1}{36}, E\left(a_{2}\right)<E\left(a_{i}\right)(i=1,3), a_{2}$ is not the best solution;

3) When $P\left(\theta_{2}\right)=\frac{1}{36}, a_{i}(i=1,3)$, leads to $E\left(a_{2}\right)=E\left(a_{i}\right)$, program $a_{2}$ is the same with the others.

$P\left(\theta_{2}\right)=\frac{1}{36}$ is called critical probability.

The stability analysis provides a great convenience for the choice of decision scheme. As long as the probability value of $p_{2}$ is not less than the critical value, the original scheme $a_{2}$ is still valid. Actually, it will be better if the difference between the probability $p_{2}$ and the critical value $\frac{1}{36}$ is larger.

Because of the uncertainty of information and the change of objective conditions, there is still a large scope of application in the decision making of the $p_{2}$.Then this program is with stronger stability.

\section{Conclusions}

Among the various activities of enterprises, purchasing is an important input link, which is of great significance 
to the enterprise cost control. For average-tech industries, the cost of the logistics procurement should be between $30 \%$ and $50 \%$. For high-tech industries, the proportion of the purchase cost is generally low. For the mature simple technology, procurement costs may be even higher. And the formation of the inventory of logistics is often the burden of enterprises. So we should use the scientific management method to further optimize the management of logistics purchasing. In this paper, we study the applicable principles of mathematical expectation under risk decision. Through a concrete example, we do simulation and get a reasonable purchase plan. The optimal plan can get the maximum expected profit or minimum expected loss.

Actually, the reality problem is more complex than our model since it has much more random events. In this paper we only use mathematical expectation to simplify the problem. But the market is changing; the demand is random and the probabilities of a variety of states are also changing. In the future, we will consider conditional probability and variance analysis for solving the risk-decision problem in logistics purchasing, and further consider the application in mathematics and system software, establish the database model, in order to do quantitative analysis of the common risks in logistics procurement.

\section{References}

[1] Ellram, L.M. and Cooper, M.C. (1993) Characteristics of Supply Chain Management and the Implication for Purchasing and Logistics Strategy. International Journal of Logistics Management, 4, 13-24. http://dx.doi.org/10.1108/09574099310804957

[2] Wang, F. and Wang, S. (2010) Applying Logistics to Construction Material Purchasing and Inventory. Third International Conference on Services in Emerging Markets, 2, 199-201. http://dx.doi.org/10.1109/icsem.2010.141

[3] Hansson, S.O. (2006) Evaluating the Risk Decision Process. Toxicology, 218, 100-111. http://dx.doi.org/10.1016/j.tox.2005.10.003

[4] Morrish, D.G. (2011) Probability and Statistics. Pearson Press.

[5] Natali, H. and Yuri, Y. (2011) Mathematical Modeling in Economics, Ecology and the Environment. China Renmin University Press.

[6] Deng, J.X. (2013) The Application of Mathematical Expectation in Reality. Applied Mechanics \& Materials, 310, 588591. http://dx.doi.org/10.4028/www.scientific.net/AMM.310.588

[7] Wen, J.H. and Zhang, M. (2012) Application of Mathematical Expectation in Economical Field. Research Journal of Applied Sciences Engineering \& Technology, 4, 502-509.

[8] Zhang, E.W. and Jin, G.C. (1998) Application of Probability and Statistics in the Risk Management. Journal of Shenyang Ligong University, 18, 51-53.

[9] Xu, A.X. (2012) Discussion on the Application of the Mathematical Expectation in Logistics Management. Logistics Sci-Tech, 5, 124-126.

[10] Peng, Y.Z. (2009) On the Application of the Probability Theory in Risk Decision-Making. Journal of Xi'an University of Arts \& Science, 12, 48-52. 